\title{
Digestibility evaluation of neutral sugars from hemicellulose of alfalfa hay by nylon capsule method
}

\author{
J Trinácty, B Svozil, M Simek \\ Research Institut of Animal Nutrition, Pohorelice, Videòská 699, Czech Republic
}

Utilization of forages energy with cattle depends on the digestibility of cellulose and hemicellulose. At our trial we evaluated the digestibility structural polysaccharides which occurred in hemicellulose of alfalfa hay. A new method of nylon capsule has been used for this goal.

The trial has been performed with two cows 495 and $558 \mathrm{~kg}$ live weight, mean daily yield of milk 17.2 and 15.3 litres. The cows consumed $30 \mathrm{~kg}$ of maize silage (28.07\% DM), $4 \mathrm{~kg}$ of alfalfa hay and $6 \mathrm{~kg}$ of feed mixture. The evaluation was performed in two periods. In each period 1260 capsules were applicated to each cow. The capsules diameter was $10 \mathrm{~mm}$. They were made of nylon cloth mesh size 42 microns. The capsules contained $0.0129 \mathrm{~g}$ alfalfa hay milled through a $1 \mathrm{~mm}$ screen. The capsules was introduced to the cows orally as a paper bolus. Excrements were collected in 3 hours intervals. We devided the capsules in three time intervals. When 270 capsules were found, one time interval was finished. In one period there were three time intervals. Once in 24 hours we washed excrements under running water at $4 \mathrm{~mm}$ screen and the found capsules were inserted in a treezing machine. After a period the capsules were rinsed in an automatic washing machine. The whole sum of capsules was devided according to the analysis performed. When analysing neutral sugars we needed $32 \%$ of all found capsules. The recovery of the capsules was higher than $90 \%$.

The content of arabinose, xylose, mannose, glucose and galactose was determined according Hartman (1982, Proc 7th World Cereal and Bread Congress, Prague, 471476). The method has been based on the determination of neutral sugars using gas chromatography in the form $\mathrm{O}$ trimethylsilylderivates after hydrolysis by 1-M trifluoracetic acid.

The values of digestibility of neutral sugars increased with higher time interval. Relatively low mean digestibility was at mannose $56.98 \%$ and xylose $61.33 \%$. High mean digestibility was at glucose $92.17 \%$ and galactose $89.95 \%$. The results are similar as mentioned by Wedig and col (1986, J Dairy Sci, 69, 13091316). This author identifies the following values of digestibility with dried cows consuming alfalfa hay only - arabinose $72.4 \%$, xylose $48.5 \%$, mannose $33.8 \%$, glucose $64.6 \%$ and galactose $72.4 \%$.

\begin{tabular}{ccccccccc} 
time interval & $\begin{array}{c}\text { time of } \\
\text { passage } \\
\text { (hours) }\end{array}$ & $\begin{array}{c}\text { digest. of } \\
\text { arabinose } \\
(\%)\end{array}$ & $\begin{array}{c}\text { digest. of } \\
\text { xylose } \\
(\%)\end{array}$ & $\begin{array}{c}\text { digest. of } \\
\text { mannose }\end{array}$ & $\begin{array}{c}\text { digest. of } \\
\text { glucose } \\
(\%)\end{array}$ & $\begin{array}{c}\text { digest. of } \\
\text { galactose } \\
(\%)\end{array}$ \\
\hline 1 & 24.51 & 76.01 & 51.79 & 46.59 & 90.23 & 87.24 \\
2 & 33.30 & 83.10 & 64.91 & 60.94 & 92.29 & 90.07 \\
3 & 50.35 & 84.90 & 67.30 & 63.40 & 94.00 & 92.53 \\
mean & 36.05 & 81.34 & 61.33 & 56.98 & & 92.17 & 89.95
\end{tabular}

